\title{
PERAN MASYARAKAT DALAM PENGEMBANGAN WISATA TAMAN BRONJONG WANUJOYO KIDUL DI DESA SRIMARTANI
}

\author{
Fulgensius Wedho ${ }^{1)}$, Warsiyah ${ }^{2)}$, Cuti Winarti ${ }^{3)}$ \\ ${ }^{1)}$ Mahasiswa Jurusan Teknik Lingkungan, Institut Teknologi Yogyakarta, ${ }^{23)}$ Dosen Pengajar Jurusan Teknik \\ Lingkungan, Institut Teknologi Yogyakarta \\ email: cutia.winandh@gmail.com ${ }^{3)}$
}

\begin{abstract}
ABSTRAK
Daerah Istimewa Yogyakarta merupakan daerah wisata yang banyak diminati wisatawan lokal maupun mancanegara. Salah satu objek wisata baru yang menjadi tujuan wisatawan adalah taman wisata Taman Bronjong Wanujoyo Kidul yang terletak di desa Srimartani, Kecamatan Piyungan, Kabupaten Bantul. Sebelum dimanfaatkan sebagai tempat wisata dan rekreasi, taman wisata bronjong dulu nya hanyalah tempat biasa dengan bronjong yang tertata rapih. Berkat kreatifitas masyarakat setempat, kini bronjong tersebut dijadikan tempat wisata dan rekreasi yang indah.Tujuan dari penelitian ini adalah untuk mengetahui peran serta masyarakat dalam pengembangan wisata Taman Bronjong.

Penelitian ini menggunakan teknik pengumpulan data dengan observasi dan kuisioner yang dibagikan kepada responden. Data yang diperoleh kemudian dianalisis menggunakan metode analisis deskriptif untuk mengetahui apa saja potensi yang ada serta Daya tarik, Akasesibilitas, Amenitas yang ada di wisata Taman Bronjong

Masyarakat Dusun Wonujoyo kidul sangat berperan aktif baik dalam Pengembangan wisata taman Bronjong maupun Pengelolaan wisata taman Bronjong. Dengan adanya Atraksi wisata di Taman Bronjong seperti, Taman Bunga, kebun Sayur, Aliran sungai Gewe,dan pemandangan alam sekitar wisata taman bronjong, menjadi factor pendorong wisatawan untuk berwisata ke taman Taman Bronjong. Untuk Aksebilitas di wisata Taman Bronjong sendiri sudah tergolong bagus. Fasilitas di Taman Bronjong belum mampu mendukung jumlah pengunjung dalam jumlah yang besar, khususnya ketersedian lahan parkir yang masi minim. Masyarakat Dusun Wanujoyo Kidul sangat Berperan Baik dalam Pengelolaan maupun Pengembangan Wisata Taman Bronjong

Kata Kunci: Pariwisata, Daya Tarik, Pengembangan, Taman Bronjong, Wanujoyo Kidul
\end{abstract}

\section{HE ROLE OF COMMUNITY IN THE DEVELOPMENT OF BRONJONG WANUJOYO KIDUL PARK IN SRIMARTANI VILLAGE}

\begin{abstract}
Yogyakarta Special Region is a tourist area that is in great demand by local and foreign tourists. One of the new tourist objects that have become a tourist destination is the Taman Bronjong Wanujoyo Kidul tourist park which is located in the village of Srimartani, Piyungan District, Bantul Regency. Before being used as a tourist and recreation place, the gabion tourism park was just an ordinary place with neatly arranged gabions. Thanks to the creativity of the local community, these gabions are now used as beautiful tourist and recreational spots. The purpose of this study was to determine the role of the community in the development of tourism in Taman Bronjong.

This study uses data collection techniques with observation and questionnaires distributed to respondents. The data obtained were then analyzed using descriptive analysis methods to find out what the potential is as well as the attractiveness, accessibility, and amenities that are in the tourism of Taman Bronjong.

The people of Wonujoyo Kidul Hamlet are very active in both the development of tourism in the Bronjong park and in the management of tourism in the Bronjong park. With the existence of tourist attractions in Taman Bronjong, such as flower gardens, vegetable gardens, Gewe river flow, and natural scenery around the gabion garden, it is a driving factor for tourists to travel to Taman Bronjong park. The accessibility of the Gabon Park tour itself is quite good. The facilities at Taman Bronjong have not been able to support the large number of visitors, especially the availability of parking lots which is still minimal. The people of Wanujoyo Kidul Hamlet play a very good role in both the management and development of Taman Bronjong Tourism Keywords: Tourism, Attraction, Development, Bronjong Park, Wanujoyo Kidul
\end{abstract}

\section{PENDAHULUAN}

Pariwisata adalah salah satu sektor industri yang diharapkan dapat menghasilkan devisa dan mempunyai ciri khas tersendiri dalam penanganan maupun pengelolaannya, sehingga tidak hanya sekedar modal kerja tetapi juga memerlukan suatu keahlian, ketekunan, dedikasi yang tinggi dan pandai memanfaatkan peluang yang ada dalam menjadikan pariwisata sebagai salah satu aspek yang diminati 
oleh wisatawan. Pariwisata merupakan sektor yang penting dalam mendukung perekonomian sebagai sumber pendapatan bagi negara. Pariwisata juga sebagai pengembangan sosial budaya dan mempromosikan citra bangsa di luar negeri. Pariwisata di Indonesia merupakan sektor yang cepat berkembang dan dianggap sebagai salah satu sektor ekonomi yang paling penting. Sektor ini yang diharapkan dapat menjadi penghasil devisa yang sangat besar di negara Indonesia.

D.I Yogyakarta merupakan daerah wisata yang banyak diminati wisatawan lokal maupun mancanegara. D.I Yogyakarta memiliki beragam jenis bentuk kepariwisataan, baik itu wisata budaya, wisata alam, wista kuliner, maupun wisata jenis lainnya. Dengan adanya pariwisata, tentu akan mendatangkan berbagai dampak positif antara lain dampak lingkungan, social, budaya, dan dampak ekonomi. Dari segi ekonomi adanya pariwisata membawa berbagai macam dampak meliputi dampak langsung, tidak langsung, dan lanjutan. Dampak langsungnya bagi pekerja dikawasan wisata tersebut termasuk pemerintah daerah. Dampak tidak langsung salah satunya bisa berupa meningkatnya permintaan akan transportasi umum publik, dan dampak berkelanjutannya tentu berhubungan dengan pemerintah dan masyarakat yang bekerja di bidang pariwisata ataupun tidak secara langsung tapi mendapatkan dampak positifnya. (Ikhsan, 2016).

Pengembangan pariwisata yang diprogramkan baik oleh pemerintah maupun oleh swasta akan diarahkan kepada usaha untuk meningkatkan jumlah kunjungan wisatawan karena merupakan sumber pendapatan yang cukup signifikan. Oleh karena itu sektor patiwisata perlu didukung oleh beberapa sektor penunjang pariwisata, baik dibidang transportasi maupun dibidang akomodasi serta pelayanan termasuk sektor perhotelan, dan restoran. Dengan adanya penunjang pariwisata, jumlah wisatawan yang berkunjung diharapkan semakin meningkat, yang pada akhirnya bermuara pada penciptaan lapangan kerja dan kesempatan berusaha, serta dapat pula mempengaruhi tingkat produktivitas masyarakat dalam kegiatan perekonomian, khususnya pada bidang industri pariwisata.

Wilayah kabupaten Bantul pada dasarnya memiliki banyak objek wisata yang dapat dikembangkan sebagai objek wisata rekreatif. Salah satu objek wisata baru yang menjadi tujuan wisatawan adalah taman wisata Taman Bronjong Wanujoyo Kidul yang terletak di desa Srimartani, Kecamatan Piyungan, Kabupaten Bantul. Sebelum dimanfaatkan sebagai tempat wisata dan rekreasi, taman wisata bronjong dulu nya hanyalah tempat biasa dengan bronjong yang tertata rapih. Berkat kreatifitas masyarakat setempat, kini bronjong tersebut dijadikan tempat wisata dan rekreasi yang indah.

Dengan demikian penelitian mengenai perencanaaan pengembangan daya tarik Wisata Taman Bronjong belum pernah dilakukan sehingga penelitian ini penting dilakukan sebagai langkah awal dalam pengembangan objek wisata taman bronjong.

\section{METODE PENELITIAN}

\section{Lokasi Penelitian}

Padukuhan Wanujoyo Kidul, Desa Srimartani, Kecamatan Piyungan, Kabupaten Bantul, DIY

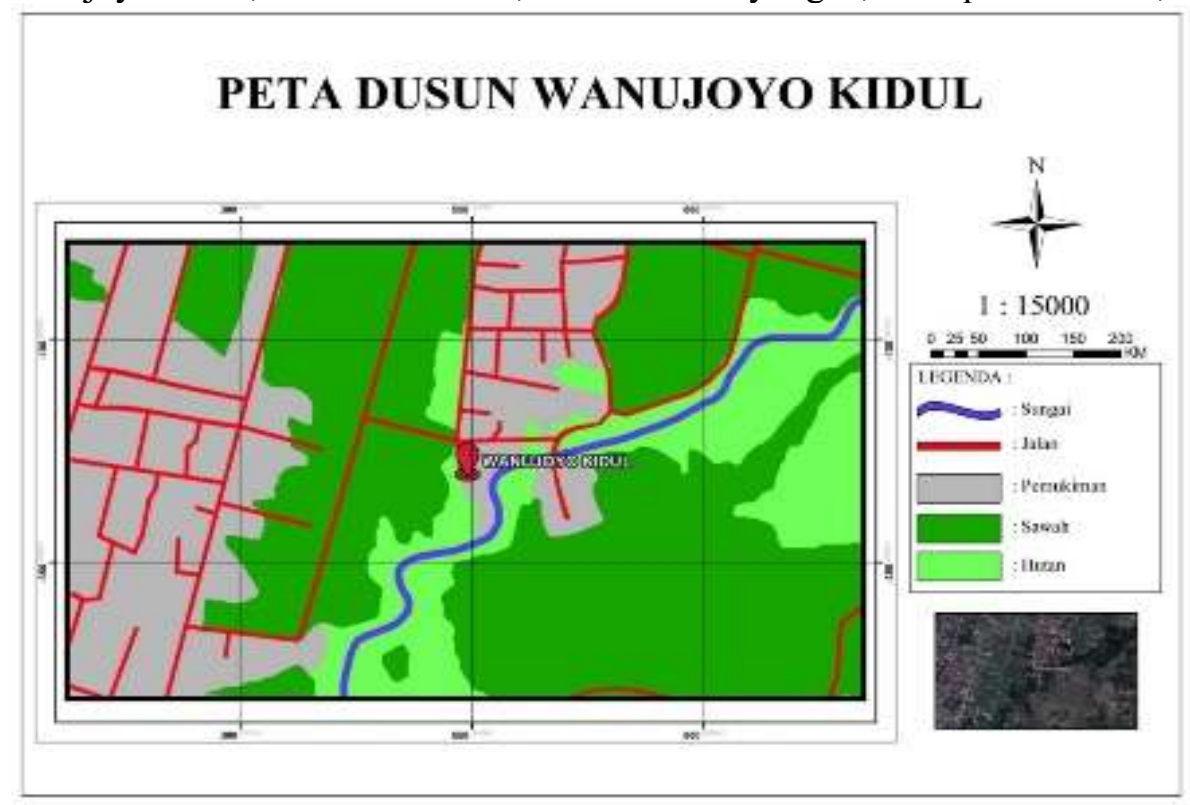

Gambar 1. Peta dukuh Wanujo Kidul 


\section{Teknik Pengumpulan Data}

1. Pengumpulan Data Primer

a) Observasi, dengan melakukan survei atau pencatatan di lapangan mengenai kondisi objek yang diamati. Dalam hal ini adalah kondisi di kawasan wisata taman bronjong.

b) Wawancara, dengan melakukan wawancara kepada para pengelola dan masyarakat sekitar kawasan wisata taman bronjong.

c) Kuisoner, ditujukan kepada responden dalam penelitian ini yaitu masyarakat sekitar kawasan wisata taman bronjong.

2. Pengumpulan Data Skunder, Data sekunder yang dimaksud yaitu luas area.

\section{Teknik Sampel}

1. Populasi

Menurut Sugiono (2010) populasi adalah wilayah generalisasi yang terdiri atas obyek/subyek yang mempunyai kualitas dan karakteristik tertentu yang ditetapkan oleh peneliti untuk dipelajari dan kemudian ditarik kesimpulan.

Sedangkan sampel adalah bagian dari jumlah karakteristik yang dimiliki oleh populasi tersebut. Populasi yang digunakan dalam penelitian ini adalah Masyarakat wanujoyo Kidul.

\section{Sampel}

Sampel penelitian ini adalah sebagian dari populasi yang diambil sebagai sumber data dan dapat mewakili seluruh populasi. Metode pengambilan sampel yang akan digunakan dalam penelitian ini adalah random sampling (secara acak), dimana sebagian masyarakat akan dijadikan sebagai responden. Namun responden yang diwawancarai terbatas, yaitu pada masyarakat yang usianya mulai dari tujuh belas tahun. Jumlah sampel minimal dalam penelitian ini selanjutnya akan dihitung dengan menggunakan rumus Slovin (Umar,2004:108) sebagai berikut:

Perhitungan Jumlah Responden,

$$
\mathrm{n}=\frac{N}{1+N e^{2}}
$$

Dimana :

$\mathrm{n}=$ jumlah responden

$\mathrm{N}=$ ukuran populasi dalam waktu tertentu $=274 \mathrm{KK}$

$\mathrm{e}=$ nilai kritis / batas ketelitian (untuk nilai e peneliti menggunakan 0,01 )

$$
\begin{aligned}
& \mathrm{n}=\frac{N}{1+N e^{2}} \\
& =\frac{274}{1+274(0,15)^{2}} \\
& =\frac{274}{1+6,165} \\
& =\frac{274}{7,165} \\
& =38,24 \text { (dibulatkan) }=38 \text { Responden }
\end{aligned}
$$

\section{Tahap Penelitian}

Penelitian dibagi dalam tiga tahap.

a) Tahap Awal (Pengambilan Data)

Tahap pengambilan data ini di ambil dari data sekunder yang berasal dari pengelola taman wisata Bronjong. Kemudian pengambilan data primer melalui observasi,wawancara,kuisioner dan pengumpulan dokumentasi serta analisis data menggunakan skala likert.

\section{Data Primer}

Data primer yaitu data yang diamati secara langsung dari masyarakat, data primer yang diperlukan terdiri dari pengelolan wisata taman bronjong, meliputi :kegiatan-kegiatan yang dilakukan masyarakat dalam sub system produksi (pemeliharan kawasan wisata taman bronjong) dalam pengumpulan data dilakukan dengan teknik yaitu :

\section{$>$ Observasi:}

Yaitu teknik pengambilan data penelitian dengan melakukan pengamatan terhadap masyarakat pada umumnya dan responden pada khususnya serta mengamati keadaan wisata taman bronjong 
Wawancara:

Yaitu dengan melakukan wawancara secara dengan responden. wawancara dilakukan dengan dua teknik yaitu, wawancara secara terstruktur dilakukan dengan data kuisoner, sedangkan wawancara bebas atau semi tersrtuktur dilakukan tanpa kuisoner mengenai hal-hal yang masih berhubungan dengan penelitian

2. Data Sekunder

Data skunder yaitu data penunjang atau data pendukung dalam penelitian. Adapun data skunder, meliputi data yang menyangkut keadaan lingkungan baik fisik, sosial dan ekonomi masyarakat (Profil Desa). Data skunder didapat dengan melakukan riset data keperpustakaan (Library search) atau dengan membaca buku-buku refrensi yang terakait dengan penelitian ini dan mengunjungi lembaga-lembaga atau instansi-instansi yang terkait dengan penelitian ini, misalnya kantor Desa atau kecamatan.

b) Tahap anlisis Data

Setelah data-data sekunder didapat kemudian dilanjutkan dengan tahap yang kedua yaitu pengolahan data, analisis secara deskriptif dan kualitatif serta pengolahan data mengunakan table skala likert. (Sumber : Sugiono, Metode Penelitian Kuantitatif, Kualitatif dan R \& D, Tahun 2012, Hal 93) Jawaban setiap instrumen yang menggunakan skala likert mempunyai gradasi dari sangat postif sampai sangat negatif yang berupa kata-kata antara lain;

$>$ Sangat Berperan

$>$ Berperans

$>$ Tidak Berperan

\section{HASIL DAN PEMBAHASAN}

Hasil Penelitian

Peran masyarakat dalam pengembangan wisata Taman Bronjong

Tabel 1. Peran Masyarakat dalam Pengembangan (Atraksi) wisata Taman Bronjong $\begin{array}{llll}\text { Jawaban } & \text { Skor Jumlah Responden yang } & \text { Persentase\% }\end{array}$ menjawab

\begin{tabular}{cccc}
\hline Tidak berperan & 1 & 0 & $0 \%$ \\
\hline Berperan & 2 & 7 & $18.4 \%$ \\
\hline Sangat berperan & 3 & 31 & $81.6 \%$ \\
\hline Jumlah & 38 & $100 \%$ \\
\hline
\end{tabular}

Sumber; Data primer 2020

Berdasarkan pada tabel di atas menunjukan bahwa responden yang menjawab tidak berperan sebanyak 0 responden atau $0 \%$, responden yang menjawab berperan sebanyak 7 responden atau $18,4 \%$ dan yang menjawab sangat berperan sebanyak 31 responden atau 81,6\%. Dari data ini dapat disimpulkan bahwa semua responden berperan dalam pengembangan Atraksi objek wisata Taman Bronjong.

Tabel 2. Peran Masyarakat dalam Pengembangan (Aksebillitas) wisata Taman Bronjong Jawaban Skor Jumlah Responden Persentase\% yang menjawab

\begin{tabular}{cccc}
\hline Tidak berperan & 1 & 0 & $0 \%$ \\
\hline Berperan & 2 & 16 & $42.1 \%$ \\
\hline Sangat berperan & 3 & 22 & $57.9 \%$ \\
\hline Jumlah & & 38 & $100.0 \%$
\end{tabular}

Sumber; Data primer 2020

Berdasarkan pada tabel di atas menunjukan bahwa responden yang menjawab tidak berperan sebanyak 0 responden atau $0 \%$, responden yang menjawab berperan sebanyak 16 responden atau $42,1 \%$ 
dan yang menjawab sangat berperan sebanyak 22 responden atau 57,9\%. Dari data ini dapat disimpulkan bahwa semua responden berperan dalam pengembangan Aksebilitas objek wisata Taman Bronjong

Tabel 3. Peran Masyarakat dalam Pengembangan (Fasilitas) wisata Taman Bronjong

\begin{tabular}{lccc}
\hline Jawaban & Skor & $\begin{array}{c}\text { Jumlah Responden yang } \\
\text { menjawab }\end{array}$ & Persentase $\%$ \\
\hline Tidak berperan & 1 & 0 & $0 \%$ \\
\hline Berperan & 2 & 10 & $26.3 \%$ \\
\hline Sangat berperan & 3 & 28 & $73.7 \%$ \\
\hline Jumlah & & 38 & $100.0 \%$ \\
\hline
\end{tabular}

Berdasarkan pada tabel di atas menunjukan bahwa responden yang menjawab tidak berperan sebanyak 0 responden atau $0 \%$, responden yang menjawab berperan sebanyak 10 responden atau $26,3 \%$ dan yang menjawab sangat berperan sebanyak 28 responden atau $73,7 \%$. Dari data ini dapat disimpulkan bahwa semua responden berperan dalam pengembangan Fasilitas objek wisata Taman Bronjong

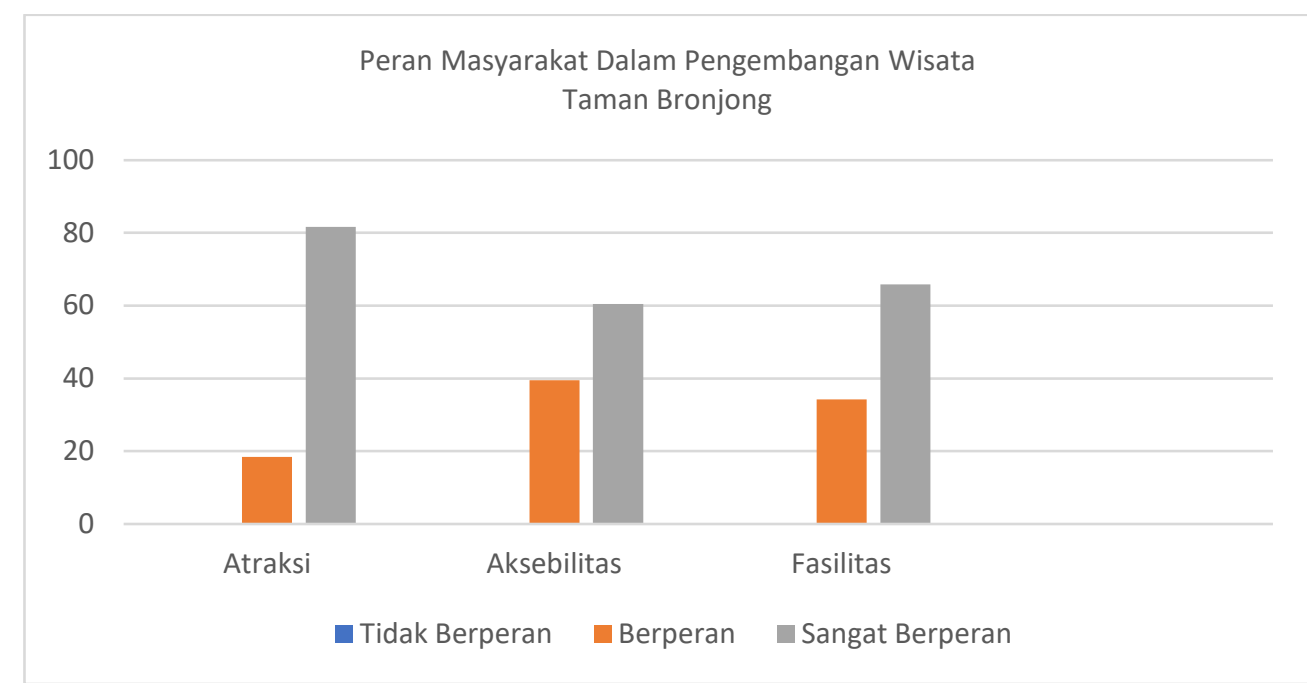

Gambar 2. Grafik Peran Masyarakat dalam Pengembangan wisata Taman Bronjong

Pembahasan Hasil Analisis Data

Tabel 4. Crosstabulation Peran Masyarakat dalam pengembangan dan pengelolaan

\begin{tabular}{|c|c|c|c|c|c|}
\hline & & & \multicolumn{2}{|c|}{ Pengelolaan } & \multirow[t]{2}{*}{ Total } \\
\hline & & & Berperan & $\begin{array}{c}\text { Sangat } \\
\text { Berperan }\end{array}$ & \\
\hline \multirow{4}{*}{ Pengembangan } & \multirow[b]{2}{*}{ Berperan } & Count & 8 & 3 & 11 \\
\hline & & $\%$ of Total & $21.1 \%$ & $7.9 \%$ & $28.9 \%$ \\
\hline & \multirow[b]{2}{*}{ Sangat Berperan } & Count & 5 & 22 & 27 \\
\hline & & $\%$ of Total & $13.2 \%$ & $57.9 \%$ & $71.1 \%$ \\
\hline \multirow[b]{2}{*}{ Total } & & Count & 13 & 25 & 38 \\
\hline & & $\%$ of Total & $34.2 \%$ & $65.8 \%$ & $100.0 \%$ \\
\hline
\end{tabular}

Dari tabel diatas dapat di jelaskan sebagai berikut

Untuk kategori berperan terdapat 8 Responden yang berperan dalam pengembangan dan juga pengelolaan wisata serta 3 Responden yang hanya berperan dalam pengembangan wisata namun sangat berperan dalam pengelolaan wisata. Untuk kategori Sangat Berperan terdapat 5 Responden yang sangat berperan terhadap pengembangan wisata dan berperan dalam pengelolaan wisata, 22 Responden yang sangat berperan dalam pengembangan Pariwisata sekaligus sangat berperan terhadap pengelolaan wisata taman Bronjong 


\section{Daya Tarik Wisata}

Sebuah lokasi wisata harus memiliki sejumlah daya tarik yang dapat menarik wisatawan untuk berwisata, berupa pemandangan alam, kekayaan flora dan fauna dan sebagainya. Berdasarkan penelitian yang telah dilangsungkan, Objek Wisata Taman Bronjong memiliki sejumlah daya tarik yang dapat dikembangkan. Beberapa daya tarik yang dimiliki Objek Wisata Taman Bronjong yakni:

1. Taman Bunga

Terdapat taman di wisata lokasi wisata Taman Bronjong. Taman ini menjadi salah satu daya Tarik wisata yang ada di Kecamatan Piyungan Kabupaten Bantul. Bisa dibilang, taman ini menjadi destinasi wisata baru di Kabupaten Bantul khususnya Kecamatan Piyungan ,desa Wanujoyo Kidul. Terdapat berbagai jenis tanaman yang ada di taman ini,mulai dari bunga, tanaman buah dan sayur serta tanaman herbal. Tanaman ini menjadi daya Tarik tersendiri dari taman ini.

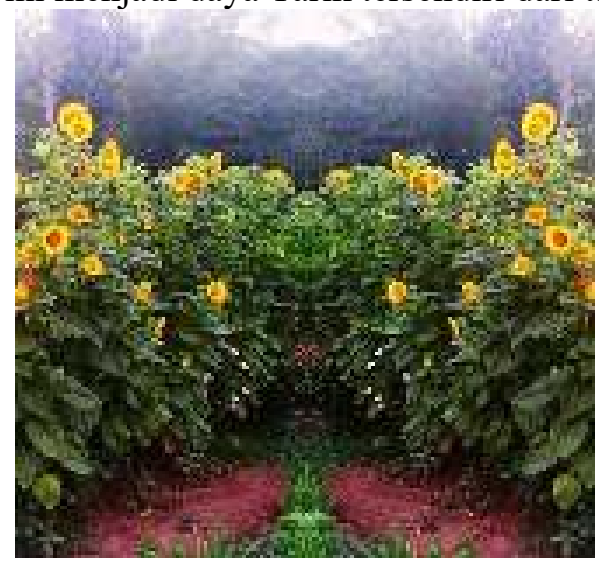

Gambar 3. Taman Bunga

2. Kebun Sayur

Terdapat Kebun sayur di lokasi wisata Taman Bronjong, Kebun sayur ini menjadi salah satu daya Tarik Wisata yang ada di Taman Bronjong, dengan adanya kebun sayur ini pengunjung bisa berwisata sambil belajar berkebun,

\section{Sungai}

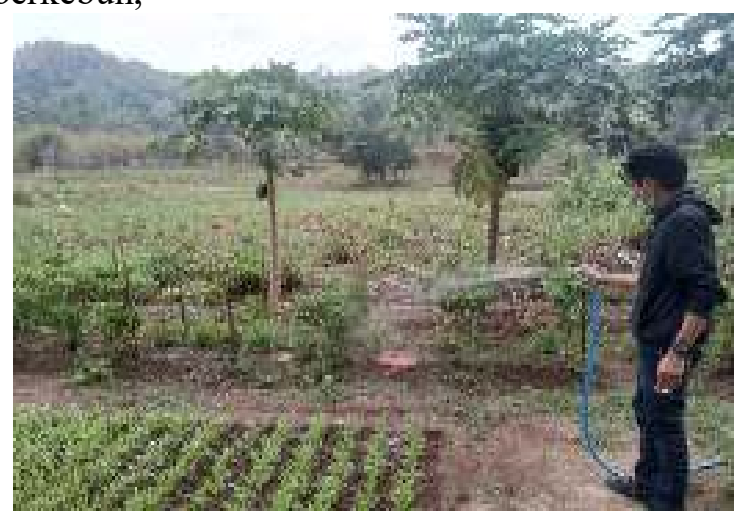

Gambar 4. Kebun sayur di lokasi wisata Taman Bronjong

Terdapat sungai di lokasi wisata taman bronjong. Sungai ini menjadi salah satu daya Tarik Wisata yang ada di daerah Taman Bronjong, sungai ini sering dimanfaatkan oleh pengunjung dan warga sekitar untuk dijadikan Spot mancing dan area bermain anak-anak, di aliran sungai ini sering di adakan Lomba mancing. Selain itu sungai ini juga sering digunakan untuk offroad dan motor cros.

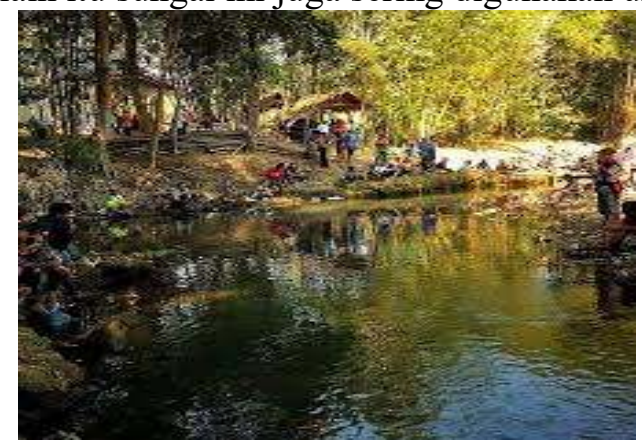




\section{Aksebilitas ( Faktor Jalan)}

a. Jarak Menuju wisata

Objek wisata Taman Bronjong terletak di Desa Wanujoyo Kidul kecamatan Piyungan. $\pm 14,5$ Kilometer dari kota Jogja.

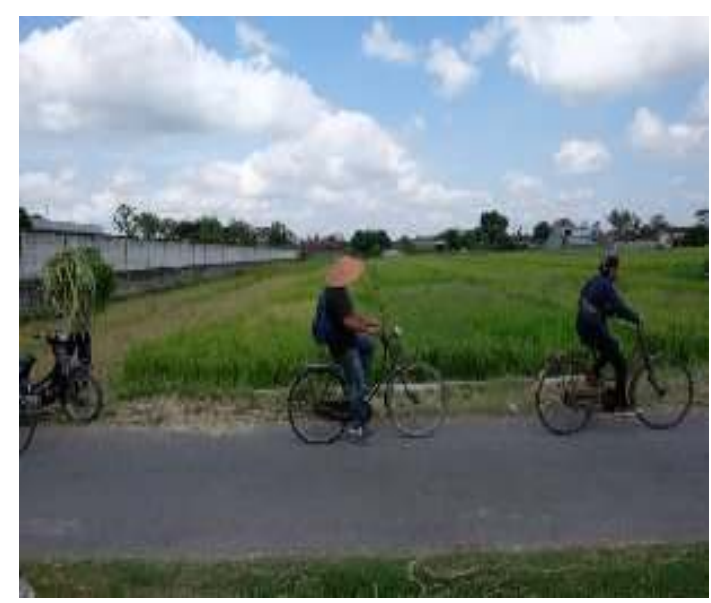

Gambar 6. Jalan Menuju Objek Wisata

b. Kondisi Jalan

Infrastruktur jalan dari kota Jogja ataupun dari bandara menuju objek wisata Taman Bronjong memiliki akses yang sangat baik karena memiliki jalan dengan aspal yang halus dan cukup lebar serta adanya rambu- rambu penunjuk arah yang begitu memadai.

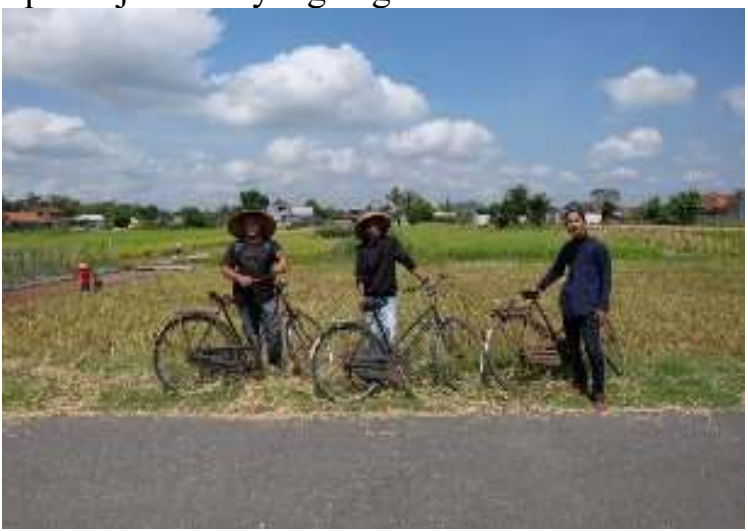

Gambar 7. Kondisi Jalan

c. Ketersediaan Angkutan

Dari kota Jogja dapat ditempuh dengan kendaraan pribadi maupun umum dengan waktu sekitar \pm 30 menit untuk menuju objek wisata Taman Bronjong.

\section{Amenitas / Fasilitas}

\section{a. Area Parkir}

Area parkir yang tersedia di kawasan wisata Taman Bronjong sudah dikelola oleh pihak pengelola tempat wisata sehingga pengunjung dapat menggunakan atau memarkir kendaraannya secara nyaman. 


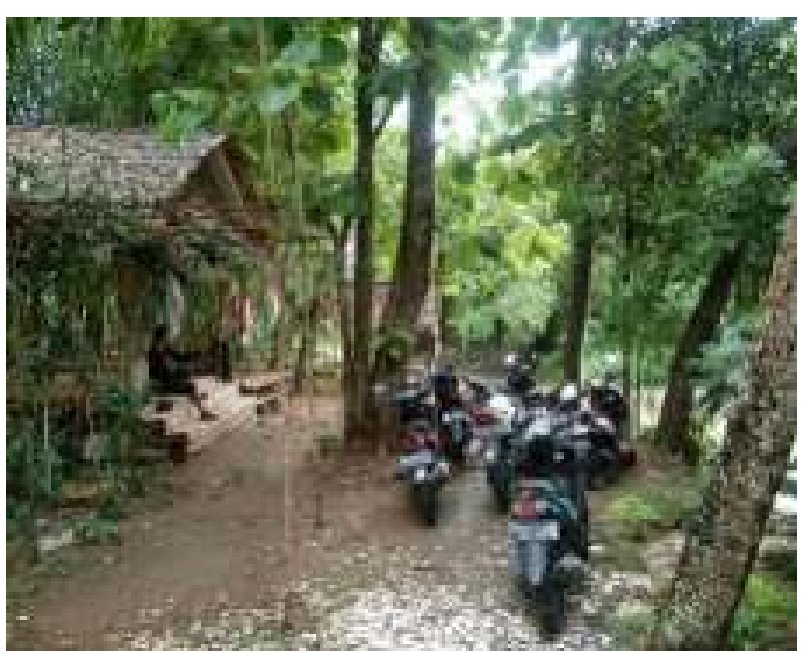

Gambar 8. Area Parkir

b. Toilet

Objek Wisata Taman Bronjong terdapat toilet umum yang disediakan sebagai sarana penunjang wisata, agar wisatawan dapat menggunakan fasilitas penunjang yang ada. Adanya fasilitas toilet umum ini cukup membantu pengunjung wisatawan.

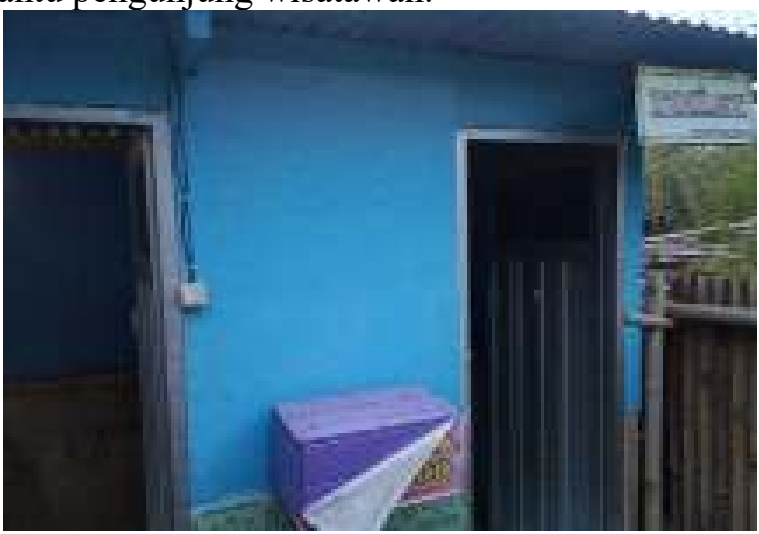

Gambar 9. Toilet Umum

\section{c. Mushola}

Objek Wisata Taman Bronjong terdapat Mushola yang disediakan sebagai sarana penunjang wisata. agar wisatawan dapat menggunakan Mushola tersebut untuk berdoa. Adanya fasilitas Mushola ini cukup membantu pengunjung wisata ,karena wisatawan yang dating bias melakukan ibadah sholat dengan nyaman.

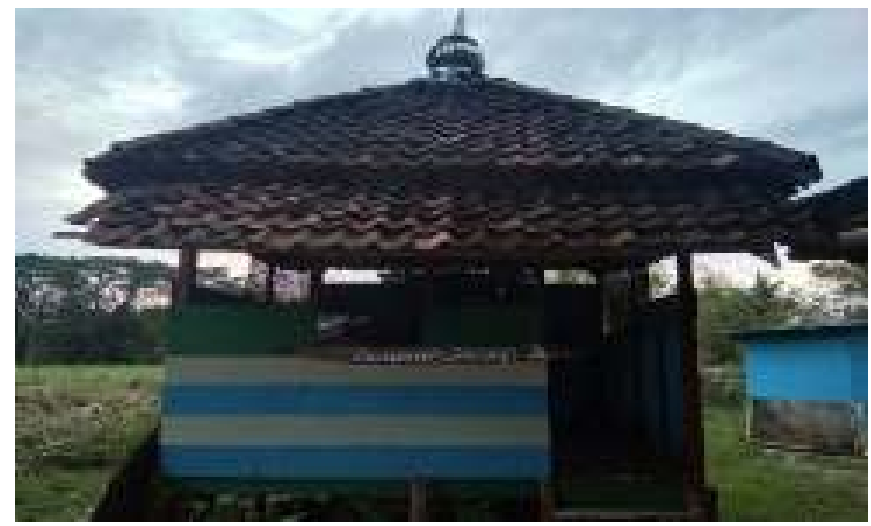

Gambar 10. Mushola

\section{d. Rumah Makan/ warung}

Dari pihak pengelola juga menyediakan warung- warung makan yang menjual aneka makanan dan minuman. Dengan adanya warung makan ini, sangat membantu pengunjung yang datang karena tidak perlu kwatir jika merasa lapar. 


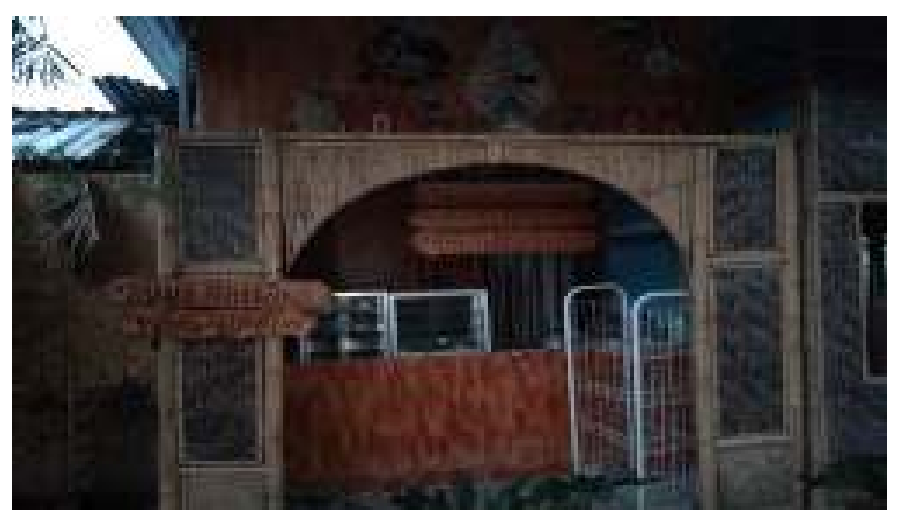

Gambar 11. Rumah makan

\section{e. Gazebo}

Dalam Objek Wisata Taman Bronjong tersedia tempat bersantai berupa gazebo. Gazebo ini terdapat di beberapa titik lokasi wisata. Adanya gazebo ini sangat menunjang pariwisata karena pengujung tidak susah untuk mencari tempat bersantai.

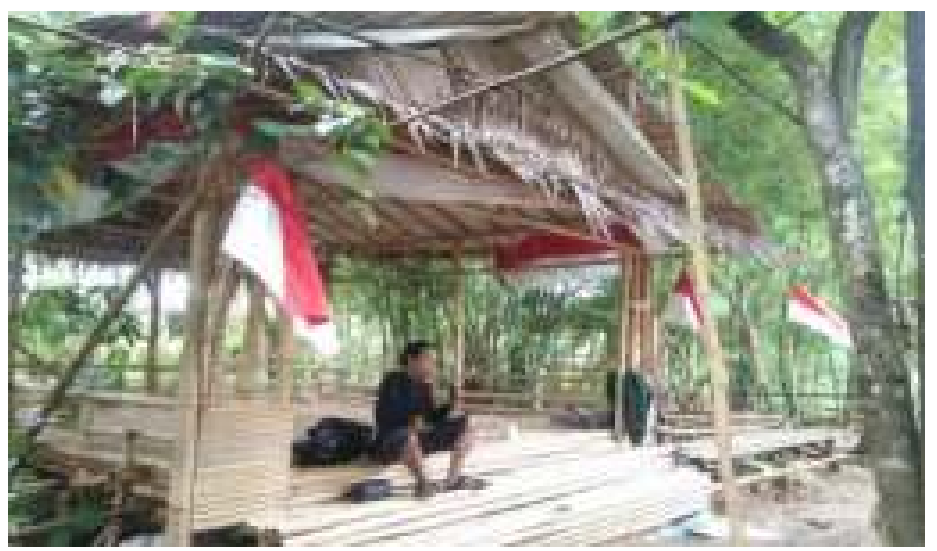

Gambar 12. Gazebo

\section{f. Tempat Sampah}

Dalam Objek Wisata Taman Bronjong, tersedia tempat sampah dibeberapa titik lokasi wisata digunakan untuk menampung sampah yang dihasilkan dari aktifitas wisata.

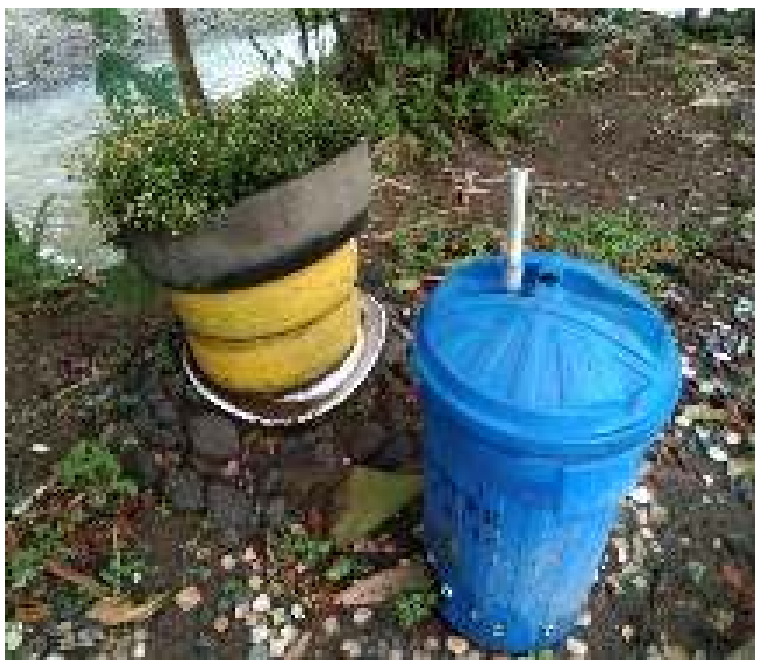

Gambar 13. Tempat sampah 


\section{g. Air bersih}

Pengelola wisata menyediakan air bersih yang berasal dari sumur bor dan di tamping dalam tendon air kemudia dialirkan menuju toilet dan taman. Adanya air bersih ini sangat mendukung pariwisata.

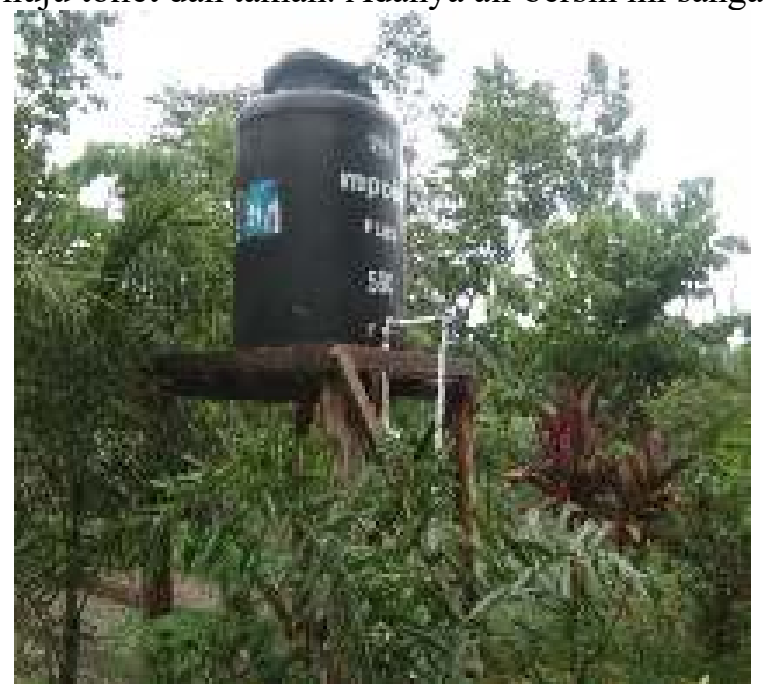

Gambar 14. Air Bersih

\section{h. Aula}

Pengelola Objek Wisata Taman Bronjong telah menyediakan tempat untuk berkumpul dan beristirahat jika wisatawan datang secara rombongan di satu titik lokasi wisata. Kondisi tempat peristirahatan relative baik.

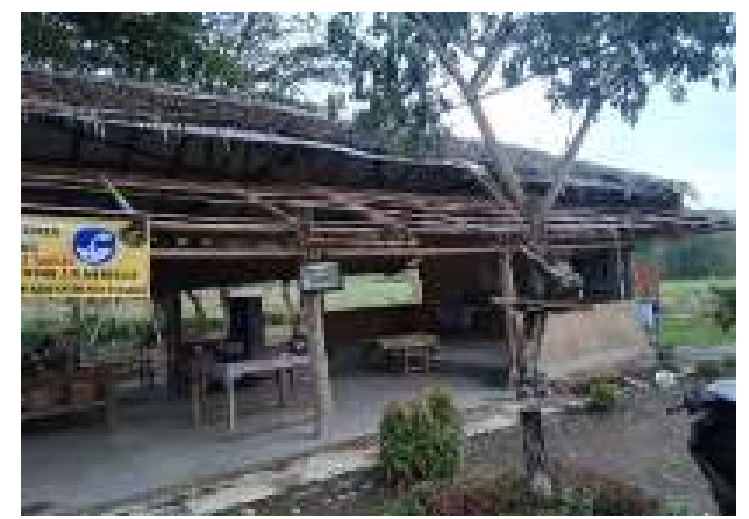

Gambar 15. Aula

\section{KESIMPULAN}

Berikut ini adalah beberapa kesimpulan yang di peroleh dari hasil penelitian ini :

1. Masyarakat Dusun Wonujoyo kidul sangat berperan aktif baik dalam Pengembangan wisata taman Bronjong maupun Pengelolaan wisata taman Bronjong

2. Dengan adanya Atraksi wisata di Taman Bronjong seperti, Taman Bunga, kebun Sayur, Aliran sungai Gewe,dan pemandangan alam sekitar wisata taman bronjong, menjadi factor pendorong wisatawan untuk berwisata ke taman Taman Bronjong.

3. Untuk Aksebilitas di wisata Taman Bronjong sendiri sudah tergolong bagus

4. Fasilitas di Taman Bronjong belum mampu mendukung jumlah pengunjung dalam jumlah yang besar, khususnya ketersedian lahan parkir yang masi minim

5. Masyarakat Dusun Wanujoyo Kidul sangat Berperan Baik dalam Pengelolaan maupun Pengembangan Wisata Taman Bronjong

\section{SARAN}

1. Wisatawan dan masyarakat lebih sadar akan pentingnya lingkungan dan wisata berkelanjutan.

2. Pihak pengelola dapat mempertahankan kealamian \& keasrian serta menambah spot spot yang bisa digunakan untuk di eksplor atau yang lainnya. 
3. Pemerintah Desadan pengelola wisata lebih bekerja sama untuk membangun amenitas seperti memperbaiki beberapa fasilitas yang kelihatan sudah mulai rusak seperti jembatan dan membenahi kembali fasilitas yang ada dan melakukan penataan taman dengan baik.

\section{DAFTAR PUSTAKA}

Ikhsan, Agung Hafiidah, (2016) Analisis Pengaruh Jumlah Obyek Wisata Jumlah Wisatwan dan PDRB Terhadap pendapatan Retribusi di 5 Kabupaten/Kota DIY "fakultas ekonomi dan bisnis universitas Muhamadya Yogyakarta, Indonesia.

Sugiono (2010) Metode Penelitian Pendidikan, Bandung: Alfabeta

Umar Husein (2004) Riset Sumber Daya Manusia, Jakarta, Gramedia 